\title{
Dinamika Kelembagaan Perhutanan Sosial di Wilayah Pehutani: Studi Kasus di KPH Telawa, Jawa Tengah
}

\section{S. Agung S. Raharjo ${ }^{1}$, Baharinawati W. Hastanti ${ }^{2}$, \& Nana Haryanti ${ }^{3}$}

1,2,3 Balai Penelitian dan Pengembangan Teknologi Pengelolaan Daerah Aliran Sungai

\begin{abstract}
Abstrak:
Perhutanan Sosial pada awalnya merupakan inisiatif Perum Perhutani yang mulai diimplementasikan pada tahun 1972. Pada tahun 2017, ada perkembangan baru terkait Perhutanan Sosial di area Perhutani yang dipelopori oleh Kementerian Lingkungan Hidup dan Kehutanan (KLHK) melalui Izin Pemanfaatan Hutan Perhutanan Sosial (IPHPS). Karena inisiatif dari kementerian, sementara implementasi IPHPS ada di dalam Kawasan Perhutani, maka di lapangan terdapat implikasi-implikasi kelembagaan yang menarik untuk dikaji. Kajian ini menggambarkan dinamika kelembagaan Perhutanan Sosial di dalam kawasan Perum Perhutani setelah keluarnya kebijakan IPHPS. Penelitian ini menggunakan pendekatan kualitatif, dengan metode pengumpulan data yang menggunakan studi literatur, wawancara dan observasi. Analisis data deskriptif dimaksudkan untuk memberikan gambaran dinamika kelembagaan sebelum dan setelah penerapan IPHPS. Tulisan ini difokuskan pada aspek kelembagaan pemerintah dan petani (yang menggarap perhutanan sosial) di level bawah (tanah garapan). Hasil penelitian ini menunjukkan struktur kelembagaan pemerintah di dalam program IPHPS lebih kompleks dibandingkan dengan program sebelumnya, yakni program Pengelolaan Sumber Daya Hutan Bersama Masyarakat (PHBM). Kelembagaan petani, di sisi lain, tidak terlalu banyak perbedaan, baik selama masa penerapan program PHBM maupun IPHPS. Kelembagaan petani masih belum mampu mandiri sehingga penguatan kelembagaan petani perlu menjadi prioritas
\end{abstract}

\section{Keywords:}

perhutanan sosial; reforma agraria; sektor kehutanan; kelembagaan

\section{Pendahuluan}

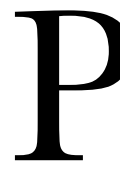

erum Perhutani merupakan salah satu pengelola kawasan hutan di Pulau Jawa. Luas kawasan hutan yang dikelola oleh Perum Perhutani mencapai

2.495.042,44 Ha, terdiri dari Hutan Produksi seluas 1.938.257,80 Ha dan

Hutan Lindung seluas 556.784,61 Ha (Subadi, 2009). Kawasan Perum Perhutani dibagi menjadi 3 devisi regional (disingkat: divre) dengan 57 Kesatuan Pemangkuan Hutan (KPH). Perencanaan pengelolaan hutan dilaksanakan oleh Pusat Perencanaan Sumber 
Daya Hutan dan dibantu Biro Perencanaan SDH dan Perusahaan (Birocan) di masingmasing divre serta Seksi Perencanaan Hutan (SPH). Salah satu sistem pengelolaan hutan yang dipraktekkan oleh Perum Perhutani adalah Perhutanan Sosial (di kalangan Perhutani biasa disingkat PS).

Embrio Perhutanan Sosial di Perum Perhutani lahir pada tahun 1972 ketika terjadi pergeseran pendekatan keamanan (security approach) menjadi pendekatan kesejahteraan (prosperity approach) (Suji, 2010). Pendekatan kesejahteraan dilakukan melalui kegiatan subsidi sarana produksi pertanian, bantuan sarana air bersih dan program mantri-lurah. Program mantri-lurah adalah program yang mengintegrasikan kegiatan mantri (KRPH-Kepala Resort Pemangkuan Hutan) dengan kegiatan Lurah (Pemerintah Desa) (Nugraheni, Harsoyo, \& Rubiyanto, 2007). Kegiatan ini terus berlanjut dan mengalami proses penyesuaian dan perbaikan seiring perkembangan jaman, pada tahun 1982 dikembangkan program Pembangunan Masyarakat Desa berupa bantuan pembangunan sarana dan prasarana biofisik desa. Pada tahun 1984 dikembangkan program PS berupa pembentukan Kelompok Tani Hutan (KTH), kegiatan Agroforestry dan Usaha Produktif.

Program Perhutanan Sosial di Perum Perhutani bersifat dinamis berkembang sesuai kondisi jaman. Pada tahun 1992 berdasarkan Keputusan Direksi Perum Perhutani No. 792/KPTS/DIR/1992 tentang Perhutanan Sosial mengatur pembangunan, pemeliharaan dan pengamanan hutan dengan melibatkan masyarakat dalam pengelolaan hutan. Program ini mengikutsertakan aparat desa, penyuluh pertanian lapangan, pemerintah daerah tingkat II (sekarang Pemda Kabupaten/Kota) dan tokoh masyarakat dalam mewujudkan program Perhutanan Sosial di satu wilayah secara terpadu lintas sektoral (Nugraheni et al., 2007).

Pada tahun 1994 dibuat program Pembinaan Masyarakat Desa Hutan Terpadu (PMDHT). Keterpaduan program ini dilakukan dengan memasukkan program Perhutanan Sosial kedalam sistem pembangunan wilayah yang dilaksanakan oleh pemerintah daerah setempat. Pada tahun 1998 dikembangkan Program Pemberdayaan Masyarakat Desa Hutan (PMDH) melalui pembentukan Lembaga Masyarakat yang Mengakar dan Mandiri (LM3) dan Koperasi Pondok Pesantren.

Pasca reformasi 1998, tepatnya pada tahun 2001 Perum Perhutani mengeluarkan program Pengelolaan Sumber Daya Hutan Bersama Masyarakat (PHBM). Program ini merupakan respon terhadap tegakan Perum Perhutani yang rusak akibat penjarahan masyarakat (Ambarwati, Sasongko, \& Therik, 2018). Program PHBM merupakan implementasi paradigma baru pengelolaan hutan Perum Perhutani yang mengedepankan pemberdayaan masyarakat melalui kesadaran berbagi peran, tanggung jawab dan hasil (Annisa \& Zunariyah, 2018). Keseluruhan program Perhutanan Sosial di atas, mulai program mantri-lurah sampai dengan PHBM, merupakan inisiatif Perum Perhutani untuk mencapai tujuan perusahaan. 
Pada tahun 2017 terbit Peraturan Menteri Lingkungan Hidup dan Kehutanan Nomor P.39/MENLHK/SETJEN/KUM.1/6/2017 tentang Perhutanan Sosial di Wilayah Kerja Perum Perhutani. Peraturan Menteri ini merupakan tindak lanjut program reforma agraria di sektor kehutanan. Peraturan menteri ini mengatur pemberian ijin pemanfaatan hutan untuk pengembangan PS di dalam kawasan yang dikelola oleh Perum Perhutani. Masyarakat dapat mengajukan permohonan pemanfaatan kawasan Perum Perhutani untuk mengembangkan Perhutanan Sosial. Jika dibandingkan dengan program Perhutanan Sosial di Perum Perhutani sebelumnya, maka program ini sedikit berbeda karena inisiator programnya bukan Perum Perhutani. Perubahan inisiator ini diduga berpengaruh terhadap kelembagaan perhutanan sosial di lapangan, salah satunya adalah berkurangnya dominasi Perum Perhutani dalam pengelolaan hutan.

Berbagai program Perhutanan Sosial, baik diinisiasi oleh Perum Perhutani maupun lembaga yang lain, sebetulnya berakar pada tujuan yang sama, yaitu untuk mengurangi dominasi negara. Dominasi negara yang terlalu kuat dianggap dapat menghambat peran serta dan kemandirian dalam bernegara (Agustina, 2013; Maladi, 2012). Dominasi negara juga terjadi di sektor pertambangan maupun kehutanan (Raharjo, Pramusinto, \& Purwanto, 2013; Zubir, 2015). Perhutanan sosial, seperti IPHPS, merupakan salah satu cara mengurangi dominasi negara dalam pengelolaan hutan sekaligus mendorong upaya pemberdayaan masyarakat dalam pengelolaan hutan. Pemberdayaan masyarakat diawali dengan memberikan Ijin Pemanfaatan Hutan untuk Perhutanan Sosial selama 35 tahun. Pemberian ijin ini merupakan jaminan legalitas hak pengelolaan hutan oleh masyarakat. Diharapkan dengan jaminan hak pengelolaan ini masyarakat akan memiliki kesadaran, dan kemampuan dalam mengenali, mengatasi, memelihara, melindungi, dan meningkatkan kesejahteraan mereka melalui pengelolaan hutan. Pengelolaan hutan bertujuan untuk mendapatkan nilai manfaat dari keberadaan hutan. Nilai manfaat yang optimal dapat diperoleh melalui pengelolaan yang baik. Pengelolaan yang baik meliputi tahapan perencanaan, pengorganisasian, kepemimpinan, dan pengendalian. Tahap-tahap pengelolaan yang baik ini harus didukung struktur organisasi yang mandiri, kuat dan efektif. Kelompok Tani Hutan (KTH) sebagai bagian organisasi pengelola hutan selama ini memiliki ketergantungan yang tinggi terhadap pemangku kawasan hutan (Perum Perhutani) sehingga kemandirian, kekuatan dan keefektifan organisasi terhambat. Kehadiran IPHPS diharapkan mampu mengubah struktur pengelola hutan dan meningkatkan kemandirian KTH sehingga tujuan akhir peningkatan kesejahteraan petani hutan dan kelestarian hutan dapat tercapai.

Apakah Program Perhutanan Sosial dengan skema IPHPS berhasil? Keberhasilan suatu program tergantung pada kehandalan kelembagaan di tingkat tapak (Budiono, 2008; Djelau, Panjaitan, \& Susdiyanti, 2014). Salah satu aspek kelembagaan adalah struktur organisasi, perubahan struktur organisasi membawa implikasi perubahan 
perilaku dan nilai-nilai intrinsik orang yang berada dalam organisassi tersebut (Suryaningsum, 2008). Penelitian ini bertujuan mengetahui dinamika perubahan struktur kelembagaan PS di kawasan Perum Perhutani di tingkat tapak pasca penetapan IPHPS dan pengaruhnya terhadap pelaksanaan PS di tingkat tapak.

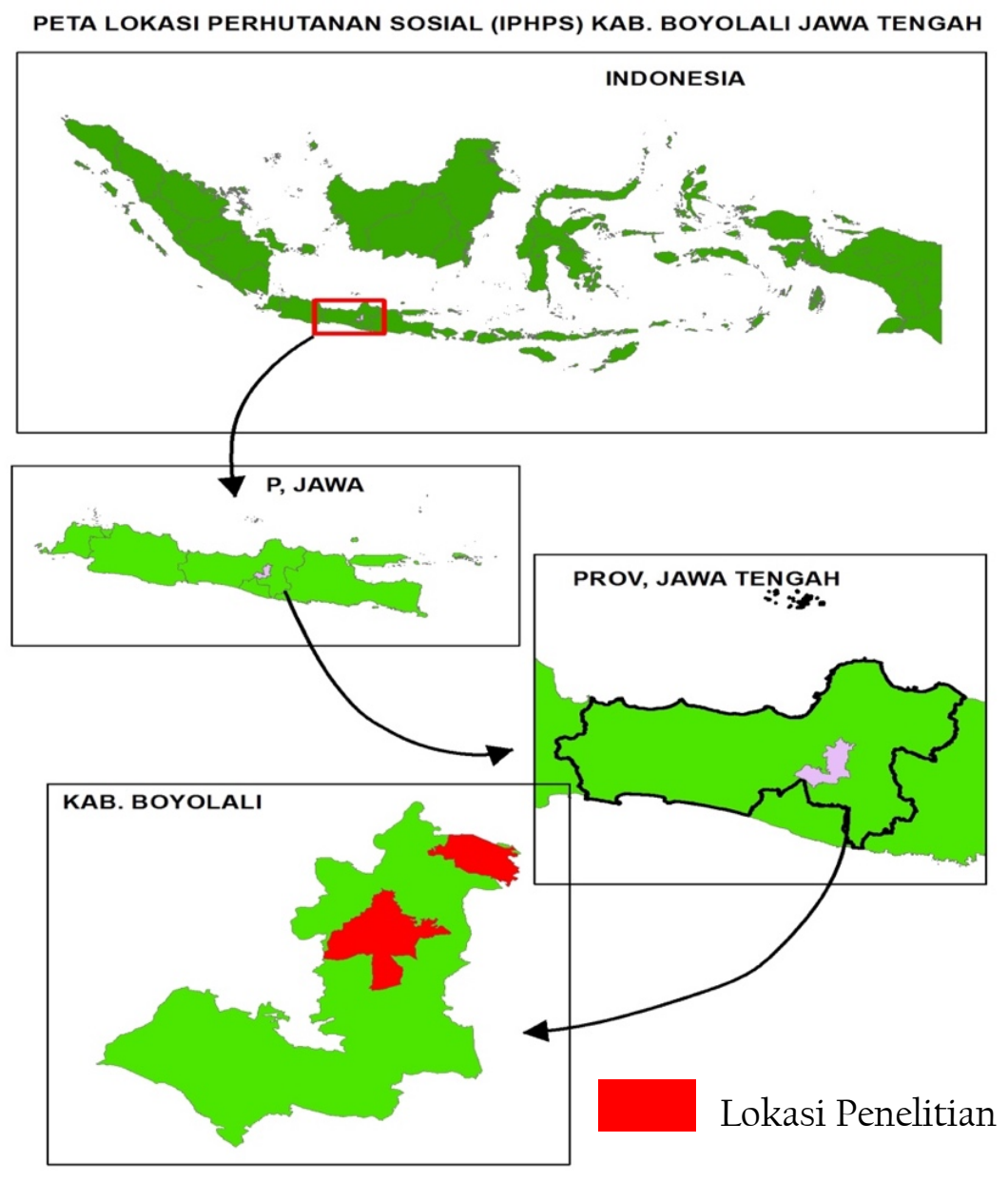

Peta 1. Lokasi Penelitian

Penelitian dilaksanakan di Desa Wonoharjo dan Desa Gondang Legi, Kecamatan Klego Kabupaten Boyolali Provinsi Jawa Tengah. Desa Wono Harjo merupakan kedudukan KTH Wono Lestari I dan KTH Wono Lestari II, Desa Gondang Legi merupakan kedudukan KTH Wono Makmur I dan KTH Wono Makmur II (Gambar 1). Penelitian dilaksanakan pada bulan Juli sampai dengan November 2019. Pengumpulan data dilakukan melalui studi pustaka, wawancara mendalam dan observasi. Wawancara mendalam dilakukan terhadap pendamping $\mathrm{KTH}$, pengurus $\mathrm{KTH}$, Perhutani KPH Telawa, Dinas Lingkungan Hidup dan Kehutanan Provinsi Jawa Tengah. Analisis data dilakukan secara deskriptif untuk memberikan gambaran yang lengkap tentang kelembagaan perhutanan sosial di wilayah Perum Perhutani. Selain itu juga dilakukan komparasi kelembagaan antara program PHBM yang merupakan inisiatif Perum 
Perhutani dengan program IPHPS yang bukan inisiatif Perum Perhutani. Perbandingan meliputi struktur kelembagaan pemerintah dan kelembagaan kelompok tani di tingkat tapak.

\section{Perhutanan Sosial Pra-IPHPS}

Sebagaimana yang sudha jamak diketahup publik, pada saat reformasi tahun 1998 terjadi penjarahan tanaman milik Perum Perhutani secara masif oleh masyarakat. Hal ini mengakibatkan banyak kawasan Perum Perhutani yang gundul (Ambarwati et al., 2018; Nugraheni et al., 2007). Kondisi ini memerlukan upaya penanganan yang serius, selain memulihkan potensi kayu yang ada juga perlu membangun kerjasama dengan masyarakat setempat agar kawasan Perum Perhutani aman dari penjarahan. Salah satu upaya tersebut adalah pemberian perlindungan hukum terhadap petani hutan penggarap lahan di dalam kawasan Perum Perhutani (Permadi, 2016). Pada tahun 2001 dikembangkanlah sistem Pengelolaan Sumber Daya Hutan Bersama Masyarakat (PHBM). PHBM dibangun berdasarkan prinsip bersama, berdaya, berbagi dan transparan (Muttaqin, 2013; Prastyo \& Hidayat, 2016). Program PHBM ini merupakan salah satu upaya resolusi konflik antara Perum Perhutani dengan masyarakat pasca reformasi (Yanuardi, 2013).

PHBM pertama kali dilaksanakan berdasarkan Keputusan Kepala PT Perhutani Unit II Jawa Timur No 939/KPTS/II/2001 tentang Petunjuk Pelaksanaan Program Pengelolaan Sumber Daya Hutan Bersama Masyarakat. Program PHBM terus diperbaiki, pada tahun 2007 Direksi Perum Perhutani mengeluarkan Keputusan Direksi Perum Perhutani No 268/KPTS/DIR/2007 tentang Pedoman Pengelolaan Sumber Daya Hutan Bersama Masyarakat Plus (PHBM PLUS). Keputusan ini bertujuan untuk meningkatkan kecepatan dan fleksibilitas pelaksanaan PHBM. Pada tahun 2009 diterbitkan Keputusan Direksi Perum Perhutani No 682/KPTS/DIR/2009 tentang Pedoman Pengelolaan Sumber Daya Hutan Bersama Masyarakat keputusan ini menetapkan prosedur kerja PHBM.

PHBM dilaksanakan berbasis pemerintah desa, terdapat kurang lebih 5.390 desa hutan di Jawa dan Madura berperanserta dalam sistem PHBM. Masyarakat di desa-desa tersebut membentuk Lembaga Masyarakat Desa Hutan (LMDH) yang menjadi wadah Kelompok Tani Hutan (KTH) yang ada di desa-desa tersebut. LMDH yang telah terbentuk sampai dengan tahun 2014 mencapai 5.289 LMDH dengan anggota 1.175.789 orang (Pambudi, Maryudi, \& Purwanto, 2017). Di KPH Telawa sampai dengan tahun 2009 terdapat 69 desa hutan yang terlibat dalam program PHBM dengan anggota sebanyak 92.605 KK (Kurniawan, 2010). Stakeholder yang terlibat dalam sistem PHBM antara lain adalah Perum Perhutani, Pemerintah daerah, LMDH dan Masyarakat. Struktur organisasi pelaksanaan PHBM dapat dilihat pada Gambar 1. 


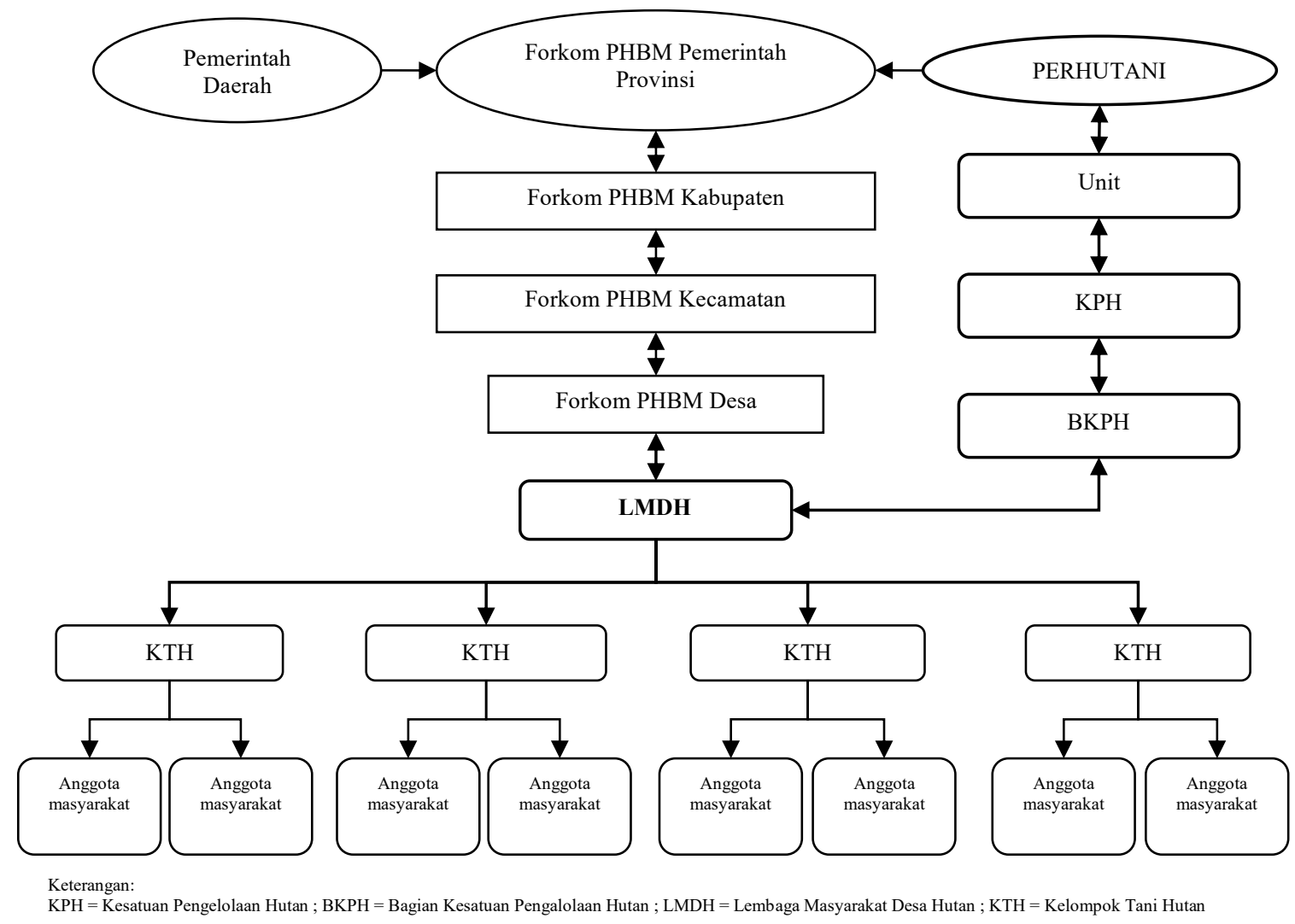

Gambar 1. Struktur Kelembagaan Pelaksanaan Perhutanan Sosial

Berdasarkan SK direksi No. 268/KPTS/DIR/2007 tentang Pedoman PHBM Plus salah satu tujuan dari PHBM adalah menyelaraskan kegiatan pengelolaan sumber daya hutan dengan kegiatan pembangunan wilayah sesuai kondisi dan dinamika sosial masyarakat desa hutan. Hal ini menunjukkan keterkaitan kelembagaan antara pemerintah daerah dengan Perum Perhutani dalam pengelolaan hutan melalui program PHBM.

Integrasi kelembagaan yang ideal ini tidak terlaksana dengan baik, karena berbagai kendala. Wilujeng (2015) menyatakan salah satu kendala pelaksanaan PHBM adalah kualitas dan kuantitas sumber daya manusia pengelola PHBM dari Dinas Kehutanan maupun Perum Perhutani sangat kurang. Selain itu juga disebutkan proses komunikasi dalam forum komunikasi pengelola PHBM di tingkat kabupaten tidak lancar. Pada tingkat tapak ternyata tidak semua petani penggarap lahan Perhutani memahami program PHBM. Hal ini mengindikasikan fungsi lembaga pengelolaan hutan dalam program PHBM tidak bekerja secara optimal. Kondisi ini juga ditemui di KPH Telawa, berdasarkan hasil wawancara diketahui bahwa sebagian besar responden tidak mengetahui keberadaan program PHBM di KPH Telawa. Masyarakat mengetahui bahwa lahan yang mereka garap merupakan lahan milik Perum Perhutani, mereka memiliki kewajiban untuk memelihara tanaman kehutanan (tanaman kayu putih atau 
tanaman jati), kemudian mereka membayar uang sewa yang besarnya bervariasi tergantung aksesibilitas lahan yang mereka garap.

Implementasi kebijakan PHBM sangat tergantung pada kuantitas dan kualitas birokrasi Perum Perhutani. Budiono (2008) menyarankan perlunya fleksibilitas administratur KPH dalam pelaksanaan PHBM selama tidak bertentangan dengan peraturan perundang undangan. Selain itu, juga disarankan untuk membuka peluang peran serta masyarakat secara luas, baik dalam hal perencanaan maupun pelaksanaan program PHBM. Kelembagaan PHBM tidak adaftif dan sangat tergantung pada birokrasi di Perum Perhutani (Kurniawan, 2010; Pambudi et al., 2017; Rosyadi \& Sobandi, 2014).

Kelembagaan petani PHBM diwadahi dalam organisasi Kelompok Tani Hutan (KTH). KTH melaksanakan usaha produktif berbasis lahan dalam kawasan Perum Perhutani dan tidak berbasis lahan seperti koperasi simpan pinjam. Beberapa KTH dalam satu wilayah pemangkuan hutan atau satu desa membentuk Lembaga Masyarakat Desa Hutan (LMDH). LMDH ini lah yang menjembatani hubungan antara masyarakat dengan Perum Perhutani (Wartiningsih \& Nuswardani, 2016). Beberapa permasalahan kelembagaan dalam pelaksanaan PHBM di KPH Telawa adalah keterbatasan SDM Keterbatasan SDM dari masing-masing LMDH, belum adanya kemandirian LMDH, peran stakeholder belum optimal dalam implementasi PHBM di lapangan dan belum optimalnya peran petugas di lapangan dalam pemberdayaan LMDH (Kurniawan, 2011).

\section{Implementasi IPHPS di KPH Telawa}

Ijin Pemanfaatan Hutan Perhutanan Sosial (IPHPS) di KPH Telawa merupakan hasil usulan kelompok masyarakat Desa Wonoharjo dan Desa Gondang Legi yang didampingi oleh LSM Rejo Semut Ireng ditingkat lokal dan Yayasan Kehutanan Indonesia di tingkat nasional. Proses pengusulan diawali dengan sosialisasi Permenhut Nomor P.39/MENLHK/SETJEN/ KUM.1/6/2017 tentang Perhutanan Sosial di Wilayah Kerja Perum Perhutani pada bulan Juni 2017 di Surakarta oleh LSM Yayasan Kehutanan Indonesia kepada pada anggota LSM Rejo Semut Ireng. Selanjutnya dilakukan sosialisasi kepada masyarakat oleh LSM Rejo Semut Ireng. Setelah sosialisasi kemudian ditindaklanjuti dengan pengumpulan data dan penyusunan dokumen usulan, yang berisi identitas masyarakat (Foto Copy KTP) dan peta kawasan yang diusulkan. Dokumen usulan diserahkan ke Kementrian KLHK pada bulan September 2017. Pada bulan Oktober dan November tahun 2017 terbitlah IPHPS untuk 4 Kelompok Tani Hutan (KTH) yaitu KTH Wono Makmur I, KTH Wono Makmur II, KTH Wono Lestari I dan KTH Wono Lestari II. SK IPHPS diserahkan secara langsung oleh Presiden RI. Luas objek IPHPS dalam SK IPHPS mengalami penurunan jika dibandingkan dengan usulan yang diajukan, usulan KTH Wono Makmur I dan II seluas 922 ha disetujui seluas 433 ha, sementara itu usulan KTH Wono Lestari I dan II seluas 459 ha disetujui seluas 295 ha, rincan luas setiap kelompok dapat dilihat pada Tabel 1. 
Tabel 1. Surat Keputusan IPHPS di KPH Telawa

\begin{tabular}{|c|c|c|c|c|}
\hline Kelompok Tani & Desa & No SK IPHPS & $\begin{array}{l}\text { Luas } \\
(\mathrm{Ha})\end{array}$ & $\begin{array}{l}\text { Jumlah } \\
\text { Penggarap } \\
\text { (org) }\end{array}$ \\
\hline Wono Lestari I & Wonoharjo & $\begin{array}{l}\text { SK.5841/MENLHK- } \\
\text { PSKL/PSL.0/11/2017 tgl.31 Oktober } \\
2017\end{array}$ & 33,0 & 59 \\
\hline Wono Lestari II & Wonoharjo & $\begin{array}{l}\text { SK.5917/MENLHK- } \\
\text { PSKL/PSL.0/11/2017 tgl.2 November } \\
2017\end{array}$ & 400,0 & 345 \\
\hline Wono Makmur I & Gondanglegi & $\begin{array}{l}\text { SK.5842/MENLHK- } \\
\text { PSKL/PSL.0/11/2017 tgl.31 Oktober } \\
2017\end{array}$ & 55,0 & 73 \\
\hline \multirow[t]{2}{*}{ Wono Makmur II } & Gondanglegi & $\begin{array}{l}\text { SK.5918/MENLHK- } \\
\text { PSKL/PSL.0/11/2017 tgl.2 November } \\
2017\end{array}$ & 240,0 & 150 \\
\hline & & Jumlah & 728,0 & 627 \\
\hline
\end{tabular}

Setelah terbit Surat Keputusan (SK) IPHPS, KTH menyusun Rencana Kerja Umum (RKU) dan Rencana Kerja Tahunan (RKT) untuk masing-masing kelompok. Penyusunan RKU dan RKT ini difasilitasi oleh pemerintah pusat melalui BLU Kementerian Lingkungan Hidup dan Kehutanan dan Balai PSKL Jabalnusra (Jawa Bali Nusa Tenggara). Perencanaan di tingkat kelompok tani ini selanjutnya disinkronisasi dengan RPKH KPH Telawa, namun proses sinkronisasi belum terlaksana karena masih menunggu finalisasi RPKH KPH Telawa jangka 2019 - 2028.

Seiring berjalannya waktu, diketahui bahwa banyak masyarakat yang mengolah lahan di dalam kawasan IPHPS namun belum terdaftar sebagai penerima SK IPHPS. Sehingga diperlukan adendum atau perubahan SK IPHPS. Pada bulan Mei tahun 2018, diajukan perubahan SK IPHPS yang mengakomodasi masyarakat penggarap yang belum masuk dalam SK IPHPS. Penambahan anggota pun tidak terhidnarkan. Di KTH Wono Lestari yang semula berjumlah 59 orang, kemudian bertambah menjadi 404 orang, dan terakhir 571 orang. Di KTH Wono Makmur yang semula 73 orang, meningkat menjadi 233 orang, dan kemudian menjadi menjadi 567 orang. Proses adendum ini masih terus berproses di Kementerian Lingkungan Hidup dan Kehutanan sampai dengan saat ini.

Berbagai kegiatan yang telah dilaksanakan oleh pemegang IPHPS di KPH Telawa dapat dilihat pada Tabel 2.

Tabel 2. Perkembangan Kegiatan IPHPS di KPH Telawa tahun 2017 - 2019

\begin{tabular}{|c|c|c|c|c|}
\hline \multirow{2}{*}{ No. } & \multirow{2}{*}{ Nama KTH } & \multicolumn{3}{|c|}{ Tahun } \\
\hline & & 2017 & 2018 & 2019 \\
\hline 1. & Wono Lestari 1 & 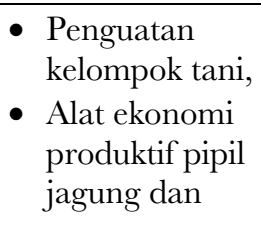 & $\begin{array}{l}\text { - Alat ekonomi } \\
\text { produktif mesin } \\
\text { suling kapasitas } 1 \text { ton } \\
\text { daun bantuan dari } \\
\text { BUPSHA (PSKL) }\end{array}$ & $\begin{array}{l}\text { - Cooking Test (uji coba } \\
\text { alat suling daun kayu } \\
\text { putih) untuk } \\
\text { mengetahui } \\
\text { rendemen dan } \\
\text { kapasitas alat suling }\end{array}$ \\
\hline
\end{tabular}




\begin{tabular}{|c|c|c|c|c|}
\hline & & $\begin{array}{l}\text { handtractor dari } \\
\text { CSR BRI, } \\
\text { - Budidaya tanaman } \\
\text { jagung }\end{array}$ & $\begin{array}{l}\text { - Pelatihan budidaya } \\
\text { tanaman dibawah } \\
\text { tegakan (empon- } \\
\text { empon) dari BDK } \\
\text { KLHK Kadipaten }\end{array}$ & $\begin{array}{l}\text { bantuan BUPSHA } \\
\text { PSKL, } \\
\text { - Inventarisir potensi } \\
\text { tanaman existing } \\
\text { (tanaman yg sudah } \\
\text { ada dari Perhutani) } \\
\text { dan potensi } \\
\text { kerjasama dengan } \\
\text { perhutani untuk } \\
\text { pengelolaan hasil } \\
\text { hutan kayu dan hasil } \\
\text { hutan bukan kayu, } \\
\text { - Bantuan benih } \\
\text { jagung BISI } 18 \text { dari } \\
\text { Kementerian } \\
\text { pertanian. }\end{array}$ \\
\hline 2. & Wono Lestari 2 & $\begin{array}{l}\text { - Penguatan } \\
\text { kelompok tani hutan } \\
\text { IPHPS, } \\
\text { - Alat ekonomi } \\
\text { produktif berupa } \\
\text { pipil jagung dan } \\
\text { handtractor dari CSR } \\
\text { BRI } \\
\text { - Budidaya Tanaman } \\
\text { jagung }\end{array}$ & $\begin{array}{l}\text { - Inventarisir tanaman } \\
\text { lama (milik } \\
\text { Perhutani) di dalam } \\
\text { kawasan IPHPS, } \\
\text { - Bantuan Alat } \\
\text { ekonomi produktif } \\
\text { berupa power traser } \\
\text { (pipil jagung } \\
\text { kapasitas besar } 16 \\
\text { pk) dari BUPSHA, } \\
\text { - Penggalian potensi } \\
\text { kelompok melalui } \\
\text { pelatihan pembutan } \\
\text { bokasi dan } \\
\text { penangkaran burung } \\
\text { dari BDK KLHK } \\
\text { Kadipaten }\end{array}$ & $\begin{array}{l}\text { - Uji coba pengolahan } \\
\text { minyak kayu putih, } \\
\text { - Penanaman bibit } \\
\text { KBR BPDASHL } \\
\text { Pamali Jratun, } \\
\text { - Bantuan benih } \\
\text { jagung BISI } 18 \text { dari } \\
\text { Kementerian } \\
\text { Pertanian }\end{array}$ \\
\hline 3. & $\begin{array}{l}\text { Wono Makmur } \\
1\end{array}$ & $\begin{array}{l}\text { - Penguatan } \\
\text { kelompok tani } \\
\text { hutan, } \\
\text { - Bantuan CSR BRI } \\
\text { alat pipil jagung dan } \\
\text { handtractor, } \\
\text { - Budidaya tanaman } \\
\text { jagung dan kedelai }\end{array}$ & $\begin{array}{l}\text { - Bantua BUPSHA } \\
\text { (Badan Usaha } \\
\text { Perhutanan Sosial } \\
\text { dan Hutan Adat) alat } \\
\text { ekonomi produktif } \\
\text { berupa Chooper } \\
\text { (pencacah rumput/ } \\
\text { pakan ternak), } \\
\text { - Penggalian potensi } \\
\text { kelompok tani } \\
\text { melalui pelatihan } \\
\text { budidaya empon } \\
\text { empon dan } \\
\text { membuat produk } \\
\text { turunannya oleh } \\
\text { BDK KLHK } \\
\text { Kadipaten, } \\
\text { - Kebun Bibit Rakyat } \\
\text { (KBR) dari } \\
\text { BPDASHL Pemali } \\
\text { Jratun Semarang }\end{array}$ & $\begin{array}{l}\text { - Penanaman bibit dari } \\
\text { hasil KBR, } \\
\text { - Bantuan benih } \\
\text { jagung BISI } 18 \text { dari } \\
\text { Kementerian } \\
\text { Pertanian }\end{array}$ \\
\hline
\end{tabular}




\begin{tabular}{|c|c|c|c|}
\hline $\begin{array}{l}\text { 4. Wono Makmur } \\
2\end{array}$ & $\begin{array}{l}\text { - Penguatan } \\
\text { kelompok tani, } \\
\text { - Budidaya tanaman } \\
\text { jagung dan Kedelai }\end{array}$ & $\begin{array}{l}\text { - Bantuan dari } \\
\text { BUPSHA (PSKL) } \\
\text { berupa alat ekonomi } \\
\text { produktif Ricemill } \\
\text { (alat giling padi), } \\
\text { - Penggalian potensi } \\
\text { kelompok tani } \\
\text { melalui pelatihan } \\
\text { budidaya jamur } \\
\text { tiram dari Balai } \\
\text { Diklat LHK } \\
\text { Kadipaten, } \\
\text { - Bantuan Kebun } \\
\text { Bibit Rakyat } \\
\text { (KBR)dari } \\
\text { BPDASHL Pamali } \\
\text { Jratun }\end{array}$ & $\begin{array}{l}\text { - Penanaman bibit dari } \\
\text { hasil KBR } \\
\text { - Bantuan benih } \\
\text { jagung BISI } 18 \text { dari } \\
\text { Kementerian } \\
\text { Pertanian }\end{array}$ \\
\hline
\end{tabular}

Sumber : Data primer (2019)

\section{Analisis Kelembagaan IPHPS di KPH Telawa}

Kelembagaan dapat berupa organisasi dan aturan (Fauziyah \& Sanudin, 2017). Dua elemen penting untuk diperhatikan dalam implementasi IPHPS, sebagiamana pada kasus KPH Telawa adalah kelembagaan pemerintah dan kelembagaan petani. Kelembagaan petani merupakan sub-sistem kelembagaan pemerintah. Kelembagaan pemerintah dalam IPHPS diatur dalam Peraturan Direktur Jenderal Perhutanan Sosial dan Kemitraan Lingkungan (PSKL) Nomor P.14/PSKL/SET/PSL.0/11/2016 tentang Pedoman Fasilitasi dan Pembentukan dan Tata Cara Kerja Kelompok Kerja Percepatan Perhutanan Sosial (Pokja PPS). Pokja PPS ini merupakan amanat dari Peraturan Menteri Lingkungan Hidup dan Kehutanan Nomor P.83/MENLHK/SETJEN/KUM.1/ 10/2016 tentang Perhutanan Sosial. Dalam implementasi Peraturan Menteri Lingkungan Hidup dan Kehutanan Nomor P.39/ MENLHK/SETJEN/ KUM.1/6/2017 tentang Perhutanan Sosial di Wilayah Kerja Perum Perhutani, peran Pokja PPS sangat penting. Pokja PPS berperan pada proses pengusulan IPHPS sampai dengan pelaksanaan dan evaluasi program. Pokja PPS merupakan kelompok kerja yang membantu fasilitasi dan verifikasi kegiatan percepatan Perhutanan Sosial. Dalam melaksanakan tugasnya Pokja PPS dapat mebangun jaringan kerja dan forum multi pihak Perhutanan Sosial.

Berdasarkan hasil observasi dan wawancara dapat diidentifikasi berbagai pihak yang terlibat dalam pelaksanaan IPHPS di KPH Telawa. Para pihak tersebut adalah BPDASHL (Balai Pengelolaan Daerah Aliran Sungai dan Hutan Lindung) Pemali Jratun, Balai Pendidikan dan Pelatihan Lingkungan Hidup dan Kehutanan Kadipaten, BUPSHA (Bina Usaha Perhutanan Sosial dan Hutan Adat)/(PSKL), Kementerian Pertanian, BRI, Perum Perhutani, Kelompok Tani Hutan, Pemerintah Desa, LSM pendamping. Para pihak ini bekerja secara terpisah-pisah, tidak terintegrasi dalam satu 
program bersama yang saling terhubung. Hubungan antar para pihak bersifat sangat cair tergantung pada keaktifan pendamping. Hal ini sangat berbeda dengan apa yang direkomendasikan dalam Perdirjend PSKL Nomor P.14/PSKL/SET/PSL.0/11/2016 tentang Pedoman Fasilitasi dan Pembentukan dan Tata Cara Kerja Kelompok Kerja Percepatan Perhutanan Sosial (Pokja PPS). Perbandingan kelembagaan menurut Perdirjend PSKL Nomor P.14/PSKL/SET/PSL.0/11/2016 dengan kelembagaan yang berjalan di lapangan dapat dilihat di Gambar 2.

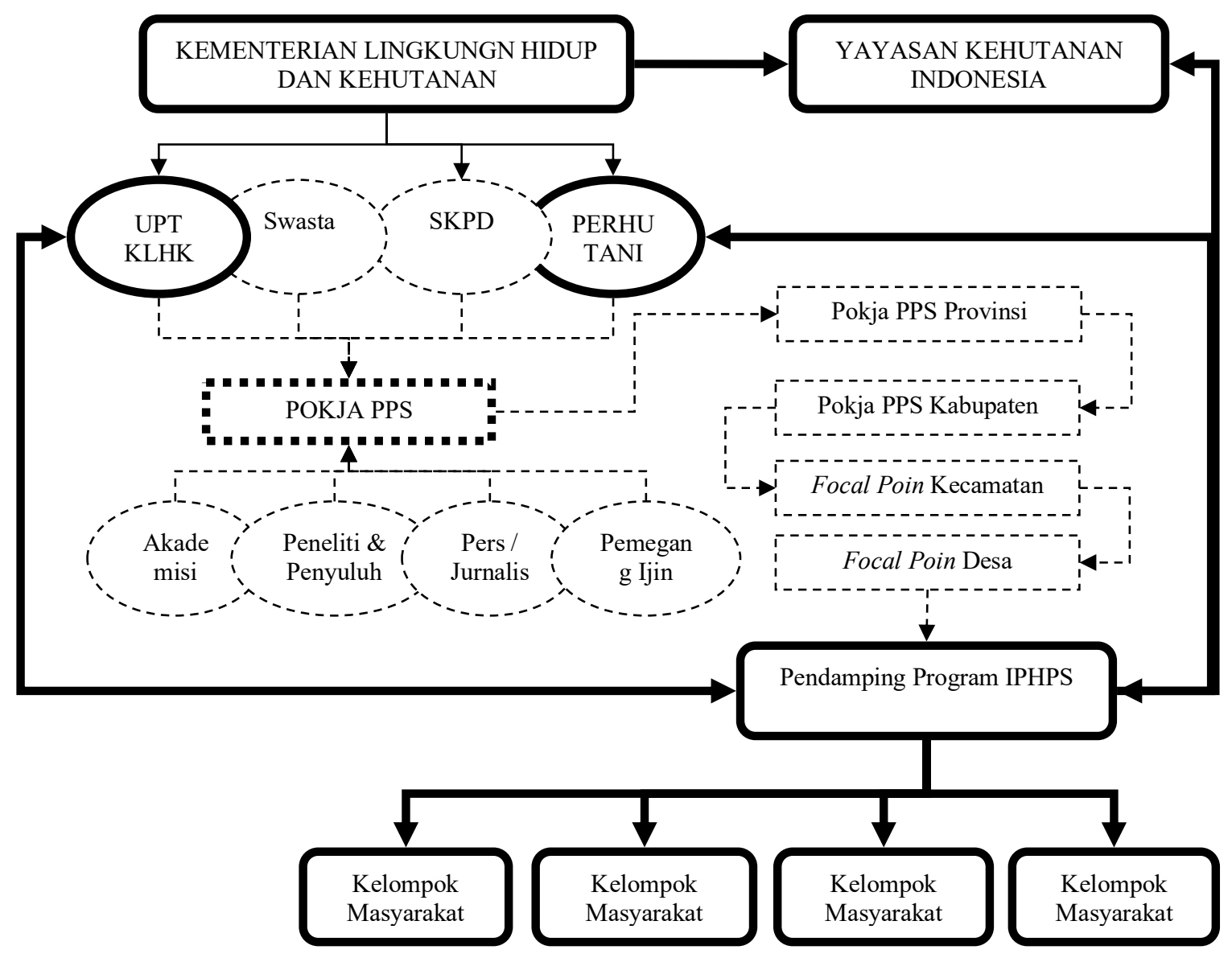

Gambar 2. Kelembagaan IPHPS menurut Perdirjend PSKL Nomor P.14/PSKL/SET/PSL.0/11/2016 dan Kelembagaan di Lapangan

Pada Gambar 2 dapat dilihat kelembagaan pemerintah yang ideal sesuai dengan Perdirjend PSKL Nomor P.14/PSKL/SET/PSL.0/11/2016 namun yang terjadi di lapangan hanya para pihak yang bergaris tebal saja yang berperan aktif, yaitu KLHK, Yayasan Kehutanan Indonesia, UPT KLHK, Perhutani, Pendamping Program IPHPS dan kelompok masyarakat. Hasil temuan di atas menunjukkan kelembagaan pemerintah di tingkat tapak belum terbentuk dan berjalan secara optimal.

Ditingkat tapak yang memiliki peran penting dalam program IPHPS di KPH Telawa adalah masyarakat dan pendamping. Berdasarkan Pasal 20 Peraturan Menteri KLHK Nomor P.39 Tahun 2017, pendamping berkewajiban untuk melakukan fasilitasi 
bagi kelompok binaannya berupa penyusunan berkas permohonan, penyusunan rencana pemanfaatan hutan dan rencana kerja tahunan, penguatan kembagaan dan kelola kawasan, pengembangan ekonomi produktif, penyelesaian konflik, pemulihan kawasan hutan, dan perlindungan areal kerja. Pencapaian pendamping IPHPS di KPH Telawa dapat dilihat di Tabel 3.

Tabel 3. Pencapaian Pendamping IPHPS di KPH Telawa

\begin{tabular}{|l|l|}
\hline Kewajiban Pendamping IPHPS & Keterangan \\
\hline Penyusunan berkas permohonan & $\begin{array}{l}\text { Sudah dilaksanakan sehingga keluar SK } \\
\text { IPHPS untuk 4 kelompok }\end{array}$ \\
\hline $\begin{array}{l}\text { Penyusunan rencana pemanfaatan } \\
\text { hutan dan rencana kerja tahunan }\end{array}$ & $\begin{array}{l}\text { Sudah ada (dalam proses sinkronisasi } \\
\text { dengan RPKH KPH Telawa) }\end{array}$ \\
\hline $\begin{array}{l}\text { Penguatan kembagaan dan kelola } \\
\text { kawasan }\end{array}$ & $\begin{array}{l}\text { Sudah dilaksanakan dengan } \\
\text { pembentukan kelompok tani, pertemuan } \\
\text { rutin dan }\end{array}$ \\
\hline Pengembangan ekonomi produktif & Sudah dilakukan beberapa pelatihan \\
\hline Penyelesaian konflik & $\begin{array}{l}\text { Sudah, melakukan komunikasi intensif } \\
\text { dengan perhutani sehingga tercapai } \\
\text { kesepakatan tentang tanaman kayu } \\
\text { putih yang merupakan aset perhutani. }\end{array}$ \\
\hline Pemulihan kawasan hutan & $\begin{array}{l}\text { Dalam jangka waktu 2 tahun sejak } \\
\text { diterbitkannya SK IPHPS belum ada } \\
\text { kegiatan penanaman tanaman keras } \\
\text { kayu), belum ada evaluasi pelaksanaan } \\
\text { program PS di lapangan }\end{array}$ \\
\hline Perlindungan areal kerja & $\begin{array}{l}\text { Sudah dilakukan secara tidak langsung } \\
\text { melalui penguatan kelembagaan } \\
\text { sehingga rasa memiliki penerima IPHPS } \\
\text { tinggi. Rasa kepemilikan yang tinggi } \\
\text { diharapkan dapat meningkatkan } \\
\text { kesadaran untuk melindungi areal kerja } \\
\text { miliknya. }\end{array}$ \\
\hline
\end{tabular}

Sumber: data primer 2019

Kelembagaan Petani dalam IPHPS di KPH Telawa dapat ditelusuri di KTH di dua desa, yaitu di Desa Wonoharjo dan Desa Gondang Legi. Berdasarkan SK IPHPS terdapat empat kelompok tani penerima SK IPHPS yaitu Kelompok Tani Hutan Wono Makmur I dan KTH Wono Makmur II di Desa Wonoharjo dan KTH Wono Lestari I dan KTH Wono Lestari II di Desa Gondang Legi.

Jumlah anggota KTH dalam satu SK IPHPS cukup besar sehingga dibagi menjadi kelompok-kelompok kecil yang dipimpin oleh ketua kelompok kecil. Beragam informasi dan keputusan berkaitan dengan IPHPS disampaikan kepada anggota melalui ketua kelompok kecil. Selain kelompok-kelompok kecil juga ada kelompok usaha perhutanan sosial, kelompok ini lebih khusus menjalankan usaha ekonomi produktif misal pembuatan kripik tortila oleh ibu-ibu di KTH Wono Lestari. Sama seperti program 
PHBM, KTH IPHPS juga melaksanakan usaha ekonomi produktif yang tidak berbasis lahan.

Berdasarkan data di atas, kita dapat melihat bahwa kelembagaan pemerintah pada program PHBM memiliki struktur kelembagaan yang sederhana. Pemangku kepentingan yang terlibat hanya Perum Perhutani, Pemerintah Daerah dan Masyarakat. Peran Perum Perhutani sangat dominan pada program PHBM. Sementara itu, kelembagaan pemerintah pada program IPHPS memiliki struktur yang lebih komplek dengan pemangku kepentingan yang lebih banyak, mulai dari Perum Perhutani, Kementerian LHK, Pemerintah Daerah, Swasta, LSM dan Masyarakat. Tentu saja, pelibatan lebih banyak elemen ini dimaksudkan agar pengelolaan Perhutanan Sosial dapat lebih partisipastif. Namun, dalam kasus di KPH Telawa peran pendamping (LSM Lokal) lebih dominan. Pengalaman yang mumpuni, juga jejaring dan kapabilitas berjejaring menjelaskan peran LSM yang cukup dominan tersebut.

Kelembagaan petani di tingkat tapak secara struktural tidak berbeda antara program PHBM dan IPHPS. Kelembagaan petani di KPH Telawa belum mandiri, KTH di program PHBM sangat tergantung pada Perum Perhutani sementara KTH di Program IPHPS sangat tergantung kepada pendamping (LSM Lokal). Ketergantungan KTH terhadap aktor luar menjadi hal yang umum dalam pengelolaan hutan Perum Perhutani (Utama, Sumardjo, Susanto, \& Gani, 2010). Dinamika kelembagaan perhutanan sosial di Perum Perhutani dari program PHBM menjadi program IPHPS belum mampu meningkatkan kemandirian KTH sebagai pengelola hutan. Kemandirian KTH menjadi salah satu permasalahan yang harus diselesaikan dalam program perhutanan sosial di wilayah Perum Perhutani.

\section{Penutup}

Berdasarkan temuan dan pembahasan dapat disimpulkan bahwa struktur kelembagaan pemerintah pada program IPHPS lebih kompleks dibandingkan dengan kelembagaan pemerintah pada program PHBM, sehingga banyak organ-organ yang tidak berfungsi secara optimal. IPHPS memang dimaksudkan lebih partisipatif, tetapi dalam praktiknya juga menjadi lebih rumit. Sementara, petani dan kelembagaan petani dalam kedua program perhutanan sosial di Perum Perhutani, yaitu PHBM dan IPHPS, tidak memiliki banyak perbedaan. Kelembagaan petani kurang mandiri dan sangat tergantung pada kehadiran pihak ketiga sebagai fasilitator. Hal ini mengakibatkan pelaksanaan program IPHPS di lapangan tidak maksimal. Perubahan struktur kelembagaan yang terjadi dalam perhutanan sosial di Perum Perhutani belum memberikan dampak signifikan terhadap kemandirian kelompok tani hutan. 


\section{Ucapan Terima Kasih}

Penulis mengucapkan terimakasih kepada Aris, Asep dan Santi dalam pelaksanaan pengambilan data di lapangan. Penulis juga mengucapkan terimakasih kepada Perum Perhutani KPH Telawa, pengurus KTH Wono Lestari I dan II, Pengurus KTH Wono Makmur I dan II, pendamping KTH IPHPS serta pemerintah Desa Gondang Legi dan Desa Wonoharjo.

\section{Pendanaan}

Penelitian ini didanai oleh APBN, melalui Balai Penelitian dan Pengembangan Teknologi Pengelolaan Daerah Aliran Sungai.

\section{Daftar Pustaka}

Agustina, S. (2013). Konsistensi Penyelenggara Sistem Pemerintahan Daerah Menurut Perspektif Konstitusional. Jurnal Cakrawala Hukum, 18(1), 59-71.

Ambarwati, M. E., Sasongko, G., \& Therik, W. M. A. (2018). Dynamics of The Tenurial Conflict in State Forest Area (Case in BKPH Tanggung KPH Semarang). Sodality: Jurnal Sosiologi Pedesaan, 6(2).

Annisa, W. R., \& Zunariyah, S. (2018). Perubahan Pola Pengelolaan Hutan oleh Masyarakat di Desa Kaligunuting (Studi Kasus PHBM di Desa Kaligunting, Kecamatan Mejayan, Kabupaten Madiun, Jawa Timur). Fournal of Development and Social Change, 1(1), 76-86.

Budiono, A. (2008). Kebijakan Perum Perhutani Kesatuan Pemangkuan Hutan Saradan dalam Pengelolaan Hutan Berbasis Partisipasi Masyarakat Melalui Program Pengelolaan Hutan Bersama Masyarakat.

Djelau, I., Panjaitan, P. B. P., \& Susdiyanti, T. (2014). Kajian Kelembagaan Terhadap Keberhasilan Kelompok Tani Hutan Rakyat di Desa Durjela Kecamatan Pulaupulau Aru Kepulauan Aru, Maluku. Furnal Nusa Sylva, 14(1), 43-54.

Fauziyah, E., \& Sanudin, S. (2017). The Effectiveness of Private Forest Institutional and Policy in Banjarnegara and Banyumas Regency. Furnal Wasian, 4(2), 79-88.

Kurniawan, A. (2010). Implementasi Program Pengelolaan Hutan Bersama Masyarakat (PHBM) di Kawasan KPH Telawa: studi kasus di LMDH Sumber Rejeki, Makmur Sejati, Trubus Lestari dan Yosowono. Universitas Negeri Semarang.

Maladi, Y. (2012). Dominasi Negara Sebagai Sumber Konflik Agraria di Indonesia. Masalah-Masalah Hukum, 41(3), 432-442.

Muttaqin, A. (2013). Ekonomi-Politik Hutan Kemasyarakatan (Kajian Pengelolaan Hutan berbasis Hak-Hak Produktif Masyarakat Sekitar). KOMUNIKA: Jurnal Dakwah Dan Komunikasi, 7(2).

Nugraheni, S. A. G., Harsoyo, Y., \& Rubiyanto, P. A. (2007). Kontribusi Perum Perhutani Terhadap Kesejahteraan MAsyarakat Desa Hutan Serta Potensi Kemitraanya.

Pambudi, R., Maryudi, A., \& Purwanto, R. H. (2017). Implementasi Dialog Otentik Dalam Pengelolaan Hutan Di Bkph Ngarengan KPH Pati Perum Perhutani Divisi Regional Jawa Tengah (Authentic Dialogue Implementation on Forest Management in Bkph Ngarengan KPH Pati Perum Perhutani Central Java Regional Division). Jurnal Manusia Dan Lingkungan, 24(1), 46-54.

Permadi, I. (2016). Perlindungan Hukum Terhadap Petani Penggarap Tanah Negara 
Milik Perum Perhutani. Arena Hukum, 9(2), 225-251.

Prastyo, E. E., \& Hidayat, K. (2016). Pola Kemitraan Antara Perum Perhutani Dengan

Masyarakat Desa Hutan (Studi Kasus Program PKPH di Desa Kucur Dau, Kabupaten Malang). HABITAT, 27(3), 139-149.

Raharjo, S. A. S., Pramusinto, A., \& Purwanto, R. H. (2013). Sejarah Dominasi Negara Dalam Pengelolaan Cendana Di Nusa Tenggara Timur (History of State Domination on Cendana Management in Nusa Tenggara Timur). Furnal Manusia Dan Lingkungan, 20(1), 1-10.

Rosyadi, S., \& Sobandi, K. R. (2014). Relasi Kuasa Antara Perhutani dan Masyarakat dalam Pengelolaan Sumber Daya Hutan di Banyumas: Kepentingan Bisnis VS

Community Empowerment. Komunitas: International Fournal of Indonesian Society and Culture, 6(1), 47-56.

Subadi. (2009). Tiga Setengah Abad Pengelolaan Tanah Kawasan Hutan di Jawa (Pendekatan Sejarah dan Politik Hukum Pada Masa Kolonial) Subadi. Jurnal Sosial, 10(1), 1-11.

Suji, S. (2010). Refleksi Pemberdayaan Desa Hutan Studi Refleksi Pelaksanaan Pemberdayaan Masyarakat Desa Kawasan Hutan di KPH Padangan Kabupaten Bojonegoro. FSEP (fournal of Social and Agricultural Economics), 4(2), 22-38.

Suryaningsum, S. (2008). Perspektif Struktur Organisasi (Tinjauan Sebagai Pengubah Perilaku). Furnal Pendidikan Akuntansi Indonesia, 6(1), 63-74.

Utama, S., Sumardjo, S., Susanto, D., \& Gani, D. S. (2010). Dinamika Kelompok Tani Hutan pada Pengelolaan Hutan Produksi Bersama Masyarakat di Perum Perhutani Unit I Provinsi Jawa Tengah. Jurnal Penyuluhan, 6(1).

Wartiningsih, W., \& Nuswardani, N. (2016). Pembentukan LMDH: Upaya Mencegah Konflik antara Perum Perhutani dan Masyarakat Sekitar Hutan. Arena Hukum, 8(3), 447-463.

Wilujeng, E. (2015). Implementasi Kebijakan Pengelolaan Hutan Bersama Masyarakat (PHBM) dalam Rangka Pelestarian Hutan Di KPH Blora. Kebijak. Dan Manaj. Publik, $3,1-10$.

Yanuardi, Y. (2013). Konflik Antara Negara dan Masyarakat Sekitar Hutan Pasca Pelaksanaan Kebijakan Pengelolaan Hutan Bersama Masyarakat. Informasi, 39. https://doi.org/10.21831/informasi.v0i2.4444

Zubir, Z. (2015). Rontoknya Dominasi Negara di Tambang Batu Bara Ombilin Sawahlunto. Furnal Ilmu Sosial Mamangan, 3(2), 15-26.

\section{Tentang Penulis}

S. Agung S. Raharjo adalah peneliti BPPTPDAS Bidang Sosial Ekonomi dan Kebijakan Hutan, Kementerian Lingkungan Hidup dan Kehutanan Republik Indonesia.

Baharinawati W. Hastanti adalah Peneliti BPPTPDAS Bidang Antropologi, Kementerian Lingkungan Hidup dan Kehutanan Republik Indonesia.

Nana Haryanti adalah Peneliti BPPTPDAS Bidang Sosiologi Lingkungan, Kementerian Lingkungan Hidup dan Kehutanan Republik Indonesia. 